\title{
In Response to Morris et al.'s "Neuroleptic Malignant Syndrome Developing after Acute Overdose with Olanzapine and Chlorpromazine"
}

Dear Editor,

Morris et al.'s interesting and valuable case report [1] invites further observations and speculations about this mysterious syndrome: we still do not know if neuroleptic malignant syndrome (NMS) involves an abnormal degree of heat generation (and if so from where), or if there is a failure of heat dissipation. It is not even clear that NMS is a primarily hyperthermic syndrome, and this report supports the idea it may not be. The term hyperthermia is not usually precisely defined: elevated temperature is not a significant problem until it reaches $\sim 40^{\circ} \mathrm{C}$ and, as in this case, many patients with diagnosed NMS do not exceed $39^{\circ} \mathrm{C}$, even with only conservative treatment [2]. Therefore, NMS is a misleading term: it is hardly justified to call the syndrome malignant, it occurs frequently without dopamine antagonist drugs of any sort [3], and it is often not hyperthermic.

This report is especially interesting because it documents the deterioration of the mental and neurological state in the absence of significant hyperthermia (maximum $39^{\circ} \mathrm{C}$ ); and it shows how changes unrelated to hyperthermia become life threatening early in development of the syndrome.

The usefulness of bromocriptine is unclear, and in this case seemingly of no benefit, despite early initiation. Bromocriptine is not only a dopamine agonist but also a serotonin 5-HT2A agonist [4]. This property promotes hyperthermia, because 5-HT2A receptor activation mediates hyperthermia in serotonin toxicity, and worsens the outcome in other models of hyperthermia like malignant hypothermia $(\mathrm{MH})$ and heatstroke [5]; conversely, 2A antagonism improves such states. A DA agonist that is also a 5HT2A antagonist, like apomorphine [6], may be preferable, the theoretical rationale being that D2 agonism promotes heat loss [7]. This has been reported as an efficacious strategy in the NMSlike condition, Parkinsonism-hyperpyrexia syndrome (PHS) [8].

\section{REFERENCES}

1. Morris E, Green D, Graudins A. Neuroleptic malignant syndrome developing after acute overdose with olanzapine and chlorpromazine. J Med Toxicol. 2009;5(1):24-26.

2. Lee JW. Catatonic variants, hyperthermic extrapyramidal reactions, and subtypes of neuroleptic malignant syndrome. Ann Clin Psychiatry. 2007;19(1):9-16.

3. Thomas A, Onofrj M. Akinetic crisis, acute akinesia, neuroleptic malignant-like syndrome, Parkinsonism-hyperpyrexia syndrome, and malignant syndrome are the same entity and are often independent of treatment withdrawal. Mov Disord. 2005;20(12):1671.

4. Cussac D, Boutet-Robinet E, Ailhaud MC, et al. Agonistdirected trafficking of signalling at serotonin 5-HT2A, 5-HT2B and 5-HT2C-VSV receptors mediated Gq/11 activation and calcium mobilisation in CHO cells. Eur J Pharmacol. 2008;594(1-3): 32-38.

5. Chang CP, Chen SH, Lin MT. Ipsapirone and ketanserin protects against circulatory shock, intracranial hypertension, and cerebral ischemia during heatstroke. Shock. 2005;24(4): 336-340.

6. Newman-Tancredi A, Cussac D, Quentric Y, et al. Differential actions of antiparkinson agents at multiple classes of monoaminergic receptor. III. Agonist and antagonist properties at serotonin, 5-HT(1) and 5-HT(2), receptor subtypes. J Pharmacol Exp Ther. 2002;303(2):815-822.

7. Cox B, Kerwin R, Lee TF. Dopamine receptors in the central thermoregulatory pathways of the rat. J Physiol. 1978;282: 471-483.

8. Onofrj M, Thomas A. Acute akinesia in Parkinson disease. Neurology. 2005;64(7):1162-1169.

Ken Gillman, MRCPsych (retired)

PO Box 86

Bucasia

Queensland 4750

Australia

Email:kg@matilda.net.au 